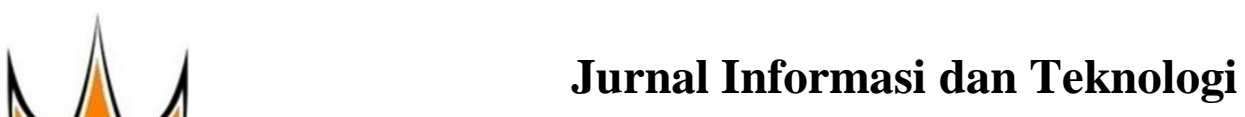

http://www.jidt.org

2021 Vol. $3 \quad$ No. $4 \quad$ Hal: $167-173$

e-ISSN: 2714-9730

\title{
Klasifikasi Penerima Bantuan Pangan Non Tunai Menggunakan Metode Decision Tree
}

\author{
Nopi Purnomo ${ }^{1 \bowtie}$, Sarjon Defit ${ }^{2}$, Yuhandri $^{3}$ \\ ${ }^{1}$ Independent Researcher \\ ${ }^{2,3}$ Universitas Putra Indonesia YPTK Padang \\ nopipurnomo2020@gmai1.com
}

\begin{abstract}
Non-Cash Food Assistance is one of the government programs that has changed its name from the RASKIN or RASTRA program which is given to poor families every month by providing an electronic account to buy food at a seller that has been determined by the village government in collaboration with Bank Mandiri. The food assistance given to the beneficiary families is a form of government concern in accordance with the criteria determined by the Ministry of Social Affairs of the Republic Indonesia. The problem that often occurs in the Cipang Kiri Hulu Village Government was the difficulty in determining families who deserve to be given the non-cash food assistance in every year, so that it can cause messy and also protests from the people due to the large number of beneficiary families who are not on target. This study was conducted to classify families who receive the non-cash food assistance so that the results of this study can be used as a reference in making decisions whether appropriate or not to receive the non-cash food assistance in Cipang Kiri Hulu Village. The method that used was classification with the Decision Tree C4.5 Algorithm by using 14 attributes. The data used in this study was data from observations at the research location and interviews directly at the homes of families who received the noncash food assistance in 2021 where there were 62 population data that have been presented in the csv file. The analysis of this study used the Rapid Miner Software version 9.5.001. The result of this research was to get 3 Rules. The rule was obtained from the final result of the decision tree's form.
\end{abstract}

Keywords: Classification, Non-Cash Food Assistance Recipients, Decision Tree, C4.5 Algorithm, Rapid Miner.

\begin{abstract}
Abstrak
Bantuan Pangan Non Tunai merupakan salah satu program pemerintah yang beralih nama dari program RASKIN atau RASTRA yang diserahkan setiap bulannya kepada keluarga kurang mampu dengan memberikan akun elektronik untuk proses pembelian bahan pangan pada pedagang yang telah ditentukan oleh pemerintah desa yang bekerja sama dengan Bank Mandiri. Adapun bantuan yang diserahkan pada keluarga penerima manfaat sebagai bentuk kepedulian dari pemerintah sesuai dengan kriteria yang telah ditentukan oleh Kementrian Sosial Republik Indonesia. Masalah yang sering terjadi di Pemerintahan Desa Cipang Kiri Hulu adalah sangat sulitnya dalam menentukan penerima yang layak untuk bantuan pangan non tunai disetiap tahunnya, sehingga menimbulkan kekacauan dan protes dari masyarakat dikarenakan banyaknya penerima bantuan yang tidak tepat sasaran. Penelitian dilakukan untuk mengklasifikasikan penerima bantuan pangan non tunai agar hasil penelitian dapat dijadikan acuan dalam pengambilan keputusan layak atau tidaknya dalam menerima bantuan pangan non tunai di Desa Cipang Kiri Hulu. Metode yang digunakan adalah Klasifikasi dengan Algoritma Decision Tree C4.5 menggunakan 14 atribut. Data yang digunakan dalam penelitian ini adalah data hasil observasi dilokasi penelitian dan melakukan wawancara secara langsung kerumah penduduk penerima bantuan pangan non tunai tahun 2021 sebanyak 62 data penduduk yang telah disajikan dalam file csv. Analisa dalam penelitian ini menggunakan tools Software Rapid Miner versi 9.5.001. Hasil dari penelitian ini adalah mendapat 3 Rule. Rule tersebut didapatkan dari hasil akhir bentuk pohon keputusan.
\end{abstract}

Kata kunci: Klasifikasi, Penerima Bantuan Pangan Non Tunai, Decision Tree, Algoritma C4.5, Rapid Miner.

(C) 2021 JIdT

\section{Pendahuluan}

kurang mampu dengan kondisi sosial ekonomi terendah program pemerintah yang beralih nama dari program Keluarga Penerima Manfaat (KPM) BPNT, nama Keluarga Miskin (RASKIN) atau Keluarga Sejahtera keluarga yang masuk dalam Daftar Penerima Manfaat (RASTRA) yang diserahkan setiap bulannya kepada (DPM) BPNT dan ditetapkan oleh Kementerian Sosial keluarga kurang mampu dengan memberikan akun (Pedoman Umum Bantuan Pangan Non Tunai, 2019) elektronik untuk proses pembelian bahan pangan pada [2]. Adapun dalam peraturan pemerintah tentang pedagang yang telah ditentukan oleh pemerintah desa pelaksanaan upaya penanganan fakir miskin atau yang bekerja sama dengan Bank Mandiri. Adapun kurang mampu melalui pendekatan wilayah yaitu bantuan yang diserahkan pada keluarga penerima Peraturan Pemerintah Nomor 63 Tahun 2013 tentang manfaat sebagai bentuk kepedulian dari pemerintah Pelaksanaan Upaya Penanganan Fakir Miskin Melalui yaitu seperti beras dan telur [1].
Pendekatan Wilayah (Lembaran Negara Republik 
Indonesia Tahun 2013 Nomor 157), Tambahan berdasarkan Usia, Berat Badan, Hemoglobin, Tekanan Lembaran Negara Republik Indonesia Nomor 5449), Darah. Hemoglobin dengan nilai gain tertinggi Pasal 2 Pemerintah dan Pemerintah Daerah (0.861212618) merupakan variabel yang paling bertanggung jawab terhadap pelaksanaan Penanganan menentukan keberhasilan melakukan donor darah [10]. Fakir Miskin. Dalam Pelaksanaan Penanganan Fakir Elfaladonna \& Rahmadani, (2019) Hasil penelitian Miskin atau Kurang Mampu, masyarakat sangat menggunakan metode Classification-Decision Tree dan berperan penting, sesuai dengan ketentuan peraturan Algoritma C.45 adalah mengklasifikasikan beberapa perundang undangan [3].

Data Mining adalah proses ataupun kegiatan untuk mengumpulkan sejumlah data yang berukuran besar kemudian mengekstraksi data tersebut menjadi suatu informasi-informasi yang nantinya dapat digunakan [4]. Data Mining bertujuan mencari trend atau pola yang diinginkan dalam database yang berukuran besar untuk membantu dalam pengambilan keputusan pada waktu yang akan datang [5].

atribut terlebih dahulu dan semua atribut akan dijadikan acuan dalam penelusuran hasil sehingga penderita dapat memprediksi sendiri apakah penyakit diabetes yang diderita adalah penyakit diabetes turunan atau tidak turunan [11]. Hasil penelitian menggunakan metode Klasifikasi dengan algoritma C4.5 adalah pengolahan dengan menggunakan 259 data alumni dari 3 fakultas dapat pemperoleh hasil klasifikasi jenis pekerjaan di pemerintahan dan swasta. Sehinga dengan hasil tersebut dapat dijadikan sebagai ilmu pengetahuan

Klasifikasi merupakan suatu proses menemukan model dalam mengambil dan mempertimbangkan untuk yang menjelaskan atau membedakan konsep atau kelas sebuah keputusan di Universitas Muhammadiyah data, agar dapat memprediksi kelas suatu objek yang Yogyakarta dengan baik [12].

tidak diketahui kelasnya [6].

Hasil penelitian menunjukan bahwa dengan Decision Tree adalah pohon keputusan classifier yang menggunakan algoritma C4.5 dapat memprediksi mengklasifikasikan data ke dalam label kelas yang keterlambatan dalam pembayaran sumbangan telah ditentukan. Sebuah pohon keputusan adalah pembangunan pendidikan sekolah atau disebut dengan struktur sederhana di mana setiap node non-terminal SPP dengan baik, menggunakan data variabel jumlah merupakan tes atau keputusan dan dianggap item data pendapatan, tabungan keluarga, latar belakang [7].

Decision Tree pada penelitian terdahulu digunakan sebagai metode klasifikasi untuk membantu perusahaan memprediksi kinerja karyawan berdasarkan data karyawan diperusahaan tersebut seperti data attribut jenis kelamin, status perkawinan, peringkat jabatan, kelompok usia, jenis pekerjaan, jenis operator, pendidikan tertinggi, tahun pelayanan, jumlah anak, performa karyawan. Hasil penelitian menunjukkan ketergantungan yang tinggi antara kinerja pegawai dengan jenis pekerjaan (kontrak kerja). Artinya, karyawan didorong untuk memberikan kinerja yang baik kepada perusahaan jika karyawan tersebut telah menjadi karyawan tetap. Kemudian diperoleh kesimpulan bahwa tidak ada hubungan antara kinerja karyawan dengan gender atau peringkat jabatan. Berdasarkan hasil penelitian Data Mining dapat digunakan untuk memprediksi kinerja pegawai dengan akurat [8]. Sedangkan Supangat, dkk. (2018) Hasil metode ini adalah diperoleh hasil bahwa 79,7\% siswa memiliki berat badan normal, $12,5 \%$ siswa mengalami kekurangan berat badan, dan $7,8 \%$ siswa mengalami kelebihan berat badan. Faktor usia, berat badan, tinggi badan, BMR, dan BMI memiliki kontribusi pada penentuan kebutuhan energi pada anak, dan jenis kelaminm mempengaruhi pada proses penentuan kebutuhan konsumsi karbohidrat, protein, lemak, dan serat [9].

Dalam penelitian Irawan, (2021) Hasil penelitian dengan metode ini adalah menghasilkan nilai secara valid dan lebih akurat. Dengan adanya aplikasi data mining metode Decision Tree Algoritma C4.5, kelayakan calon pendonor darah dapat di klasifikasikan pendidikan orang tua dan serta usia orang tua. Hasil penelitian yang didapat menghasilkan tingkat akurasi dalam memprediksi adalah sebesar 73\% [13]. Hasil penelitian menggunakan metode klasifikasi dengan algoritma $\mathrm{C} 4.5$ adalah dapat mengklasifikasikan penyebab longsor dengan pengujian RapidMiner untuk mengukur akurasinya menggunakan matriks konfusi tes dan kurva KOP menghasilkan nilai akurasi sebesar 52 persen dan menghasilkan AUC (Area Under Curve) nilai 0,500 kesalahan dalam nilai keakurasian klasifikasi (Salah Klasifikasi) [14]. Hasil penelitian menggunakan metode klasifikasi Decision Tree, data responden tes TIPI diproses dengan program Data Mining, Rapid Miner. Sifat kepribadian yang dominan akan diterapkan sebagai atribut target. Hasil yang diharapkan dari studi ini adalah simulasi tes TIPI yang bisa menelaah kepribadian dominan responden secara cepat dan akurat [15].

Penelitian sebelumnya dengan metode Decision Tree C4.5 dalam menentukan rekam jejak kinerja dosen berdasarkan 3 atribut input (publikasi, pengabdian dan pengajaran) dan 1 atribut output yang bernilai kinerja "kurang" "cukup" dan "tinggi". Hasil penelitian berupa Decision Tree beserta Rules yang memberikan informasi hasil evaluasi kinerja dosen STT Harapan Medan dalam melaksanakan tri darma perguruan tinggi [16]. Fitriani, dkk. (2021) dalam penelitian menggunakan metode $\mathrm{C} 4.5$ untuk mempediksi hasil belajar siswa secara daring diwaktu pandemi COVID19 atau Corona dengan menggunakan data nilai siswa kelas XII Jurusan Multimedia dengan menganalisa data atribut absen, tugas, hasil ulangan harian dan nilai ujian di SMK Negeri 2 Padang Panjang. Hasil pengujian 
dalam penelitian dapat memprediksi hasil belajar siswa Tahapan analisa masalah ini merupakan suatu tahapan dengan sangat baik dan akurasi dalam pengujian yaitu yang dilakukan untuk dapat memahami masalah yang sebesar 83,33\%, dan sudah dapat dijadikan suatu telah ditentukan dalam ruang lingkup atau batasan panduan atau tolak ukur untuk membantu SMKN 2 masalah dalam penelitian. Peneliti diharapkan dapat Padang Panjang dalam mengambil suatu keputusan memahami masalah yang telah ditentukan tersebut [17]. Hasil penelitian menggunakan metode Klasifikasi dengan baik. Pada analisa masalah ini digambarkan dengan algoritma C4.5 menggunakan data konsumen proses untuk mengklasifikasikan data penduduk penjualan Online Shop di Palaroid Vektor dan Gift penerima Bantuan Pangan Non Tunai di Desa Cipang Joga sebanyak 100 data dan 15 data sampel konsumen, Kiri Hulu.

dapat mengklasifikasikan tingkat kepuasan pembeli dengan tingkat keakurasian sebesar $91 \%$, nilai presisi untuk memprediksi kepuasan konsumen adalah sebesar Pada tahapan ini dikemukakan tujuan yang ingin $66,67 \%$ dan nilai presisi untuk memprediksi dicapai melalui proses penelitian. Tujuan penelitian ketidakpuasan konsumen atau pembeli yaitu sebesar harus jelas dan tegas. Tujuan penelitian adalah suatu 33,3\% dan nilai dari keakurasian ini sudah sangat baik target yang akan dicapai untuk mengatasi masalahuntuk klasifikasi dan memprediksi tingkat kepuasan masalah yang ada. konsumen atau pembeli Online Shop [18].

\section{Metodologi Penelitian}

\subsection{Mempelajari Literatur}

Tahapan mempelajari literatur ini sangat penting Kerangka kerja penelitian ini merupakan suatu dilakukan agar mempunyai landasan baik secara pedoman dalam setiap langkah-langkah yang akan teoritis yang benar dan dijelaskan oleh para peneliti dan dilakukan dalam penelitian untuk meyelesaikan ahli sebelumnya. Kemudian literatur-literatur yang masalah yang berhubungan dengan klasifikasi penerima dipelajari tersebut diseleksi dan dipilih literatur mana Bantuan Pangan Non Tunai di Desa Cipang Kiri Hulu. yang akan digunakan dalam penelitian. Literatur yang Adapun langkah-langkah yang direncanakan pada diambil dari berbagai sumber yaitu berupa buku, kerangka kerja penelitian ini dapat dilihat pada Gambar artikel, jurnal ilmiah tentang Data Mining, Decision 1.

Tree, Algoritma C4.5, serta bahan bacaan lain yang

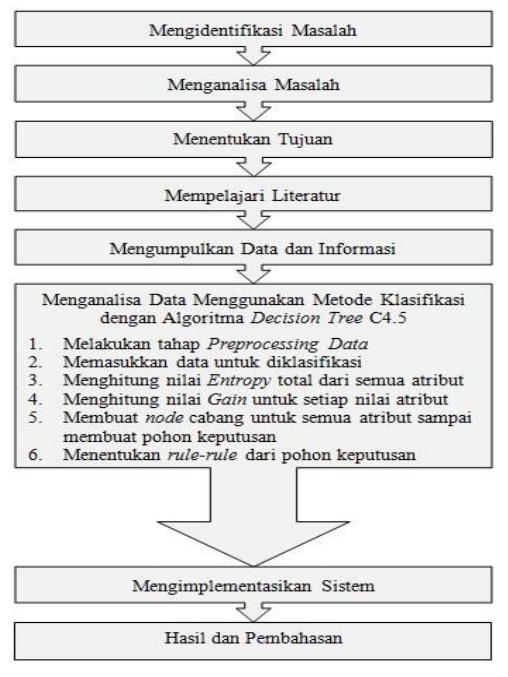

Gambar 1. Kerangka Kerja Penelitian

\subsection{Mengumpulkan Data dan Informasi}

Pengumpulan data dilakukan agar dapat memperoleh informasi sehingga tujuan dari penelitian menggunakan Metode C4.5 ini dapat tercapai. Pengumpulan data dengan melakukan observasi langsung di Desa Cipang Kiri Hulu Kecamatan Rokan IV Koto Kabupaten Rokan Hulu. Pengamatan secara langsung dilokasi penelitian untuk melihat data yang akan diproses dan data yang diambil merupakan data penerima Bantuan Pangan Non Tunai dan juga melakukan wawancara secara langsung kerumah penduduk penerima Bantuan Pangan Non Tunai di Desa Cipang Kiri Hulu.

\subsection{Menganalisa Data Menggunakan Metode Klasifikasi dengan Algoritma Decision Tree C4.5}

Agar permasalahan penelitian ini dapat dianalisa maka digunakan metode Klasifikasi dengan Model Algoritma Decision Tree C4.5 untuk mengklasifikasikan data Uraian kerangka kerja merupakan suatu uraian yang penduduk penerima Bantuan Pangan Non Tunai di terperinci terhadap masing-masing kerangka kerja yang Desa Cipang Kiri Hulu. Sebelum dianalisa data dengan telah disusun agar penelitian yang dilakukan dapat Algoritma Decision Tree C4.5, data yang dikumpulkan terlaksana secara terstruktur, baik dan jelas.

\subsection{Mengidentifikasi Masalah}

harus melakukan tahap preprocessing (data cleaning dan transformation) terlebih dahulu, sehingga menghasilkan data set berupa data training dan data Tahapan identifikasi masalah merupakan suatu tahapan testing. Setelah itu dilanjutkan dengan analisa data awal dalam penelitian. Peneliti melakukan perumusan menggunakan metode Klasifikasi dengan Model masalah dari masalah yang ditemukan pada data Algoritma Decision Tree C4.5.

penduduk penerima Bantuan Pangan Non Tunai di Desa Cipang Kiri Hulu dan memberikan batasan dari permasalahan yang akan diteliti lebih terarah.

\subsection{Mengimplementasikan Sistem}

Pada tahap ini implementasi dilakukan untuk mendapatkan pola terbaik dalam penelitian untuk menentukan penduduk layak atau tidaknya penerima 
Bantuan Pangan Non Tunai di Desa Cipang Kiri Hulu menganalisa penerima bantuan pangan non tunai yang menggunakan data training dan dibandingkan dengan layak adalah sebagai berikut:

data testing. Metode Klasifikasi dengan Model Algoritma Decision Tree C4.5 menggunakan Tools Data Mining dan untuk penelitian ini menggunakan Software Rapid Miner versi 9.5.001.

\subsection{Hasil dan Pembahasan}

Pada tahap ini akan diuraikan hasil perhitungan secara manual menggunakan metode Klasifikasi dengan Model Algoritma Decision Tree C4.5 dan kemudian dilakukan pengujian hasil yang diperoleh dari perhitungan manual tersebut menggunakan Software Rapid Miner versi 9.5.001. Hasil tersebut dapat dijadikan pedoman Pemerintahan Desa Cipang Kiri Hulu untuk tahun berikutnya

\section{Hasil dan Pembahasan}

3.1. Analisa Teknik Pengolahan Data Menggunakan Algoritma C4.5

Pada bab ini adalah suatu gambaran proses analisa untuk menyelesaikan masalah yang terjadi dan $\mathrm{j}$. menerapkan metode dan algoritma yang digunakan untuk menyelesaikan masalah pada penelitian ini. Data yang diperlukan adalah data penerima bantuan pangan non tunai di Desa Cipang Kiri Hulu pada tahun 2021. 1 Data yang nantinya akan diolah mempunyai beberapa kriteria yang merupakan syarat dalam pengolahan Data Mining dengan menggunakan teknik algoritma C4.5. Dimulai dengan perhitungan Entropy dan Gain untuk menentukan akar (root) dari pohon keputusan, sampai terbentuk pohon keputusan menganalisa jumlah penerima layak dan tidaknya penerima bantuan pangan non tunai. Pada analisa data secara manual diperlukan bantuan Software Microsoft Office Excel 2010 untuk mempermudah dalam perhitungannya. Setelah hasil pengolahan didapat, maka selanjutnya dilakukan pengujian dengan menggunakan Software Rapid Miner versi 9.5.001.

a. K1 = Luas Lantai Bangunan Tempat Tinggal Kurang dari $8 \mathrm{M} 2$ per Orang

b. $\mathrm{K} 2=$ Jenis Lantai Tempat Tinggal Terbuat dari Tanah/Bambu/Kayu Murahan

c. $\mathrm{K} 3=$ Jenis Dinding Tempat Tinggal dari Bambu/Rumbia/Kayu Berkualitas Rendah/Tembok Tanpa Displester

d. K4 = Tidak Memiliki Fasilitas Buang Air Besar/Bersama-sama dengan Rumah Tangga Lain.

e. K5 = Sumber Penerangan Rumah Tangga tidak Menggunakan Listrik

f. $\mathrm{K} 6=$ Sumber Air Minum berasal dari Sumur/Mata Air tidak Terlindung/Sungai/Air Hujan

g. $\mathrm{K} 7=$ Bahan Bakar untuk Memasak Sehari-hari adalah Kayu Bakar/Arang/Minyak Tanah

h. $\mathrm{K} 8$ = Hanya Mengkonsumsi Daging/Susu/Ayam dalam Satu Kali Seminggu

i. K9 = Hanya Membeli Satu Stel Pakaian Baru dalam Setahun

K10 = Hanya Sanggup Makan Sebanyak Satu/Dua Kali dalam Sehari

k. $\mathrm{K} 11=$ Tidak Sanggup Membayar Biaya Pengobatan Dipuskesmas/Poliklinik

1. $\mathrm{K} 12=$ Sumber Penghasilan Kepala Rumah Tangga adalah : Petani dengan Luas Lahan 500 M2, Buruh Tani, Nelayan, Buruh Bangunan, Buruh Perkebunan dan atau Pekerjaan Lainnya dengan Pendapatan Dibawah Rp. 600.000,- per Bulan

m. K13 = Pendidikan Tertinggi Kepala Rumah Tangga : Tidak Sekolah/Tidak Tamat SD/Tamat SD

n. $\mathrm{K} 14=$ Tidak Memiliki Tabungan/Barang atau aset yang Mudah Dijual dengan Minimal sebesar 500.000, seperti Sepeda Motor yang belum lunas atau Kredit/Tidak Kredit, Emas, Ternak, Kapal Motor, atau Barang Modal Lainnya.

Adapun atribut yang akan menjadi keputusan adalah Layak dan Tidak Layak.

Berdasarkan kerangka kerja penelitian yang terdapat pada metodologi penelitian di Bab 3, bahwa tahapan kerja terdiri dari mengidentifikasi masalah, menganalis Langkah-langkah dalam perhitungan menggunakan masalah, mempelajari literatur, mengumpulkan data, Metode Klasifikasi dengan Algoritma Decision Tree mengolah data, hasil dan pembahasan. Guna C4.5 adalah sebagai berikut :

memudahkan dalam penerapan metodologi, analisa dan perancangan seperti pada Gambar 2.

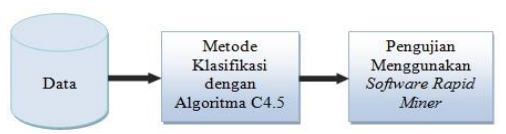

Gambar 2. Bagan Alir Analisa

\subsection{Melakukan Processing Data}

Sebelum masuk ketahap pengolahan data, data tersebut harus dibersihkan terlebih dahulu dan barulah Dimana $\mathrm{N}$ adalah set kasus atau jumlah kasus. $t$ selanjutnya melakukan cleaning data. Tahapan merupakan jumlah partisi $\mathrm{N}$ dan qr merupakan proporsi cleaning data dilakukan untuk menentukan atribut $\mathrm{Nr}$ ke $\mathrm{N}$.

mana yang digunakan dalam pengolahan data dalam penelitian. Atribut penunjang yang digunakan untuk a. Menghitung nilai Entropy total dari semua atribut

b. Menghitung nilai Gain untuk setiap nilai atribut

c. Membuat node cabang untuk semua atribut sampai membuat pohon keputusan

d. Menentukan rule-rule dari pohon keputusan

Untuk perhitungan mencari nilai entropy menggunakan rumus disajikan pada Persamaan (1).

Entropy $(N)=\sum_{1-r}^{t}-q r * \log _{2} q r$

Rumus perhitungan untuk mencari nilai gain yang disajikan pada Persamaan (2). 
Gain $(\mathrm{N}, \mathrm{M})=\operatorname{Entropy}(N)-\sum_{o=1}^{t} \frac{|N o|}{|N|} *$ Entropy $($ No $)$

(2) 3.4 Perhitungan Node 1

Dimana $\mathrm{N}$ adalah set kasus atau jumah kasus. M Setelah melakukan processing data dan tranformasi merupakan fitur atau atribut yang digunakan. $t$ data, selanjutnya masuk ketahap perhitungan nilai merupakan jumlah partisi pada atribut $M$. |No| entropy dan gain. Hasil Perhitungan dapat dilihat di merupakan jumlah pada partisi ke $\mathrm{N}$ dan $|\mathrm{N}|$ adalah perhitungan node 1 pada Tabel 1.

jumlah kasus di N.

Tabel 1. Perhitungan Node 1

\begin{tabular}{|c|c|c|c|c|c|c|c|}
\hline Node & & & $\begin{array}{c}\text { Jumlah } \\
\text { Kasus (N) }\end{array}$ & Layak (L) & Tdk Layak (L2) & Entropy & Gain \\
\hline \multirow[t]{51}{*}{1} & Total & & 42 & 28 & 14 & 0,9183 & \\
\hline & $\mathrm{K} 1$ & & & & & & 0,5691 \\
\hline & & Lebih & 15 & 2 & 13 & 0,5665 & \\
\hline & & Kurang & 27 & 26 & 1 & 0,2286 & \\
\hline & $\mathrm{K} 2$ & & & & & & 0,3293 \\
\hline & & Kayu Murahan & 17 & 17 & 0 & 0 & \\
\hline & & Semen & 25 & 11 & 14 & 0,9896 & \\
\hline & K3 & & & & & & 0.5152 \\
\hline & & Kayu Berkualitas & 24 & 23 & 1 & 0,2498 & \\
\hline & & Rendah & & & & & \\
\hline & & Tembok Tanpa & 11 & 6 & 5 & 0,99403 & \\
\hline & & Displester & & & & & \\
\hline & & Tembok di & 8 & 0 & 8 & 0 & \\
\hline & & Displester & & & & & \\
\hline & K4 & & & & & & 0,1214 \\
\hline & & Memiliki Fasilitas & 3 & 0 & 3 & 0 & \\
\hline & & BAB & 20 & & & & \\
\hline & $V_{5}$ & Tidak Memiliki & 39 & 28 & 11 & 0,8582 & \\
\hline & K5 & & & & & & 0,3019 \\
\hline & & Menggunakan & 26 & 12 & 14 & 0,9957 & \\
\hline & & $\begin{array}{l}\text { Listrik } \\
\text { Tidak Menounakan }\end{array}$ & & & & & \\
\hline & & $\begin{array}{l}\text { Tidak Mengunakan } \\
\text { Listrik }\end{array}$ & 16 & 16 & 0 & 0 & \\
\hline & K6 & & & & & & 0,166 \\
\hline & & Sumur & 4 & 0 & 4 & 0 & \\
\hline & & Sungai & 38 & 28 & 10 & 0,8315 & \\
\hline & K7 & & & & & & 0,3882 \\
\hline & & Kayu Bakar & 35 & 28 & 7 & 0,6362 & \\
\hline & & Gas LPG & 7 & 0 & 7 & 0 & \\
\hline & K8 & & & & & & 0,2132 \\
\hline & & $\mathrm{Ya}$ & 5 & 0 & 5 & 0 & \\
\hline & & Tidak & 37 & 28 & 9 & 0,8004 & \\
\hline & K9 & & & & & & 0,0386 \\
\hline & & $\mathrm{Ya}$ & 1 & 0 & 1 & 0 & \\
\hline & & Tidak & 41 & 28 & 13 & 0,9012 & \\
\hline & K10 & & & & & & 0,2132 \\
\hline & & $\mathrm{Ya}$ & 5 & 0 & 5 & 0 & \\
\hline & & Tidak & 37 & 28 & 9 & 0,8004 & \\
\hline & K11 & & & & & & 0,2729 \\
\hline & & Sanggup & 9 & 1 & 8 & 0,5033 & \\
\hline & & Tidak Sanggup & 33 & 27 & 6 & 0,684 & \\
\hline & K12 & & & & & & 0,1713 \\
\hline & & Petani & 38 & 28 & 10 & 0,8256 & \\
\hline & & Pedagang & 2 & 0 & 2 & 0 & \\
\hline & & Karyawan Swasta & 2 & 0 & 2 & 0 & \\
\hline & K13 & & & & & & 0,1051 \\
\hline & & Tidak Tamat SD & 31 & 24 & 7 & 0,7706 & \\
\hline & & Tamat SD & 9 & 3 & 6 & 0,9183 & \\
\hline & & Tamat SMA & 2 & 1 & 1 & 1 & \\
\hline & K14 & & & & & & 0,7921 \\
\hline & & $\mathrm{Ya}$ & 15 & 1 & 14 & 0,3534 & \\
\hline & & Tidak & 27 & 27 & 0 & 0 & \\
\hline
\end{tabular}

Dari hasil perhitungan pada Tabel 1 dapat diketahui bahwa atribut gain tertinggi adalah K14 dengan nilai sebesar 0.7921. Dengan demikian K14 dapat dijadikan sebagai node akar, dimana nilai atribut Tidak sudah dapat dikatakan layak, akan tetapi nilai atribut Ya masih perlu dilakukan perhitungan lagi, seperti Gambar 3.

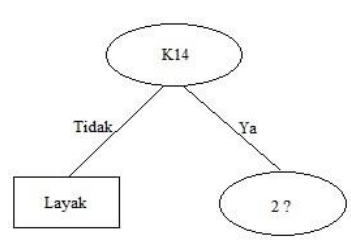

Gambar 3. Pohon Keputusan Hasil Node 1 
Selanjutnya adalah melakukan pencarian untuk K8, K9, K10, K11, K12, K13. Hasil Perhitungan dapat perhitungan Node 2 sebagai akar, sama dengan cara dilihat di perhitungan node 2 pada Tabel 2.

mencari node 1 dengan menghitung nilai entropy dari

atribut yang tersisa yaitu K1, K2, K3, K4, K5, K6, K7,

Tabel 2. Perhitungan Node 2

\begin{tabular}{|c|c|c|c|c|c|c|c|}
\hline \multicolumn{2}{|c|}{ Node } & & \multirow{3}{*}{$\begin{array}{c}\text { Jumlah Kasus (N) } \\
15\end{array}$} & \multirow{3}{*}{$\begin{array}{c}\text { Layak (L) } \\
1\end{array}$} & \multirow{3}{*}{$\frac{\text { Tdk Layak (L2) }}{14}$} & \multirow{4}{*}{$\begin{array}{l}\text { Entropy } \\
0,3534\end{array}$} & \multirow[t]{3}{*}{ Gain } \\
\hline 2 & & & & & & & \\
\hline & $\begin{array}{l}\text { K14,Ya } \\
\text { K1 }\end{array}$ & & & & & & \\
\hline & & & & & & & 0,22003 \\
\hline & & Lebih & 13 & 0 & 13 & 0 & \\
\hline & & Kurang & 2 & 1 & 1 & 1 & \\
\hline & K2 & & & & & & \\
\hline & & Kayu Murahan & 1 & 1 & 0 & 0 & 0,3534 \\
\hline & & Semen & 14 & 0 & 14 & 0 & \\
\hline & K3 & & & & & & 0.22003 \\
\hline & & Kayu Berkualitas & 2 & 1 & 1 & 1 & \\
\hline & & Rendah & & & & & \\
\hline & & Tembok Tanpa & 5 & 0 & 5 & 0 & \\
\hline & & Displester & & & & & \\
\hline & & Tembok di Displester & 8 & 0 & 8 & 0 & \\
\hline & K4 & & & & & & 0,0223 \\
\hline & & Memiliki Fasilitas BAB & 3 & 0 & 3 & 0 & \\
\hline & & Tidak Memiliki & 12 & 1 & 11 & 0,3534 & \\
\hline & K5 & & & & & & 0 \\
\hline & & Menggunakan Listrik & 15 & 1 & 14 & 0,3534 & \\
\hline & & $\begin{array}{l}\text { Tidak Mengunakan } \\
\text { Listrik }\end{array}$ & 0 & 0 & 0 & 0 & \\
\hline & K6 & & & & & & 0,0306 \\
\hline & & Sumur & 4 & 0 & 4 & 0 & \\
\hline & & Sungai & 11 & 1 & 10 & 0,4395 & \\
\hline & K7 & & & & & & 0,0635 \\
\hline & & Kayu Bakar & 8 & 1 & 7 & 0,5436 & \\
\hline & & Gas LPG & 7 & 0 & 7 & 0 & \\
\hline & K8 & & & & & & 0,0407 \\
\hline & & Ya & 5 & 0 & 5 & 0 & \\
\hline & & Tidak & 10 & 1 & 9 & 0,4689 & \\
\hline & K9 & & & & & & 0,0069 \\
\hline & & Ya & 1 & 0 & 1 & 0 & \\
\hline & & Tidak & 14 & 1 & 13 & 0,3712 & \\
\hline & K10 & & & & & & 0,04069 \\
\hline & & Ya & 5 & 0 & 5 & 0 & \\
\hline & & Tidak & 10 & 1 & 9 & 0,4689 & \\
\hline & K11 & & & & & & 0,0772 \\
\hline & & Sanggup & 7 & 1 & 6 & 0,5917 & \\
\hline & & Tidak Sanggup & 8 & 0 & 8 & 0 & \\
\hline & K12 & & & & & & 0,1713 \\
\hline & & Petani & 11 & 1 & 10 & 0,4395 & \\
\hline & & Pedagang & 2 & 0 & 2 & 0 & \\
\hline & & Karyawan Swasta & 2 & 0 & 2 & 0 & \\
\hline & K13 & & & & & & 0,22002 \\
\hline & & Tidak Tamat SD & 7 & 0 & 7 & 0 & \\
\hline & & Tamat SD & 6 & 0 & 6 & 0 & \\
\hline & & Tamat SMA & 2 & 1 & 1 & 1 & \\
\hline
\end{tabular}

Dari hasil perhitungan pada Tabel 2 dapat diketahui Semen adalah Tidak Layak karena nilai Entropy bahwa atribut gain tertinggi adalah K2 dengan nilai kedunya sudah bernilai nol, maka dari itu K2 tidak sebesar 0.353359335. Dengan demikian K2 dapat dilakukan perhitungan lagi. Pohon Keputusan yang dijadikan sebagai node akar, dimana nilai atribut Kayu terbentuk dapat diliat seperti Gambar 4.

Murahan sudah dikatakan Layak dan juga nilai atribut 


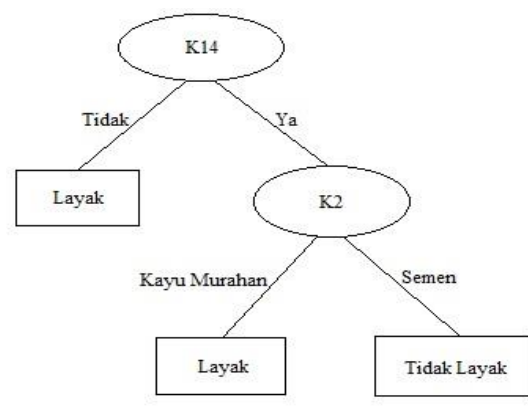

Gambar 4. Pohon Keputusan Hasil Node 2

Dari hasil perhitungan yang dilakukan, mendapatkan hasil pohon keputusan terakhir yaitu dapat dilihat pada Gambar 4, dapat dibuat rule-rule pada analisa Data Mining untuk mengklasifikasikan penerima bantuan pangan non tunai menggunakan metode Decision Tree dengan algoritma $\mathrm{C} 4.5$ adalah sebagai berikut:

1. Jika $\mathrm{K} 14=$ Tidak, maka jenis penerima bantuan $=$ Layak

2. Jika $\mathrm{K} 14=$ Ya dan $\mathrm{K} 2=$ Kayu Murahan, maka jenis penerima bantuan $=$ Layak

3. Jika $\mathrm{K} 14=\mathrm{Ya}$ dan $\mathrm{K} 2=$ Semen, maka jenis penerima bantuan $=$ Tidak Layak

\section{Kesimpulan}

Berdasarkan hasil pengujian dan perhitungan secara manual menggunakan metode Klasifikasi penerima bantuan pangan non tunai dengan algoritma Decision Tree C4.5 pada Desa Cipang Kiri Hulu, dilakukan dengan menggunakan 42 sampel data penduduk dan mendapatkan atribut akar atau root adalah $\mathrm{K} 14$, dan atribut yang menjadi cabang yaitu K12, dan kemudian atribut yang menjadi ranting atau hasil keputusan adalah layak dan tidak layak. Rule Rule tersebut didapatkan dari hasil akhir bentuk pohon keputusan.

\section{Daftar Rujukan}

[1] Ermawati, E. (2019). Algoritma Klasifikasi C4.5 Berbasis Particle Swarm Optimization Untuk Prediksi Penerima Bantuan Pangan Non Tunai. Jurnal Sistem Informasi, 8(3), 513-528. http:// doi.org/10.32520/stmsi.v8i3.576

[2] Huda, N., Hasbi, M., Susyanto, T.(2021). Seleksi Penerimaan Bantuan Pangan Non Tunai di Desa Menggunakan Metode Naïve Bayes dan Simple Additive Weighting. Jurnal Ilmiah Sinus, 19(1),39-48. http:// doi.org/10.30646/sinus.v19i1.525

[3] Irmayansyah., \& Firdaus, A. A. (2018). Penerapan Algoritma C4.5 Untuk Klasifikasi Penentuan Penerimaan Bantuan Langsung Di Desa Ciomas. Jurnal Ilmiah Teknologi - Informasi dan Sains (TeknoIS), 8(1), 17-28. http:// doi.org/10.36350/jbs.v8i1.18

[4] Oscario, Jasmir., Novianto, Y. (2019). Penerapan Algoritma C4.5 Untuk Memprediksi Kecocokan Gaya Belajar Bagi Siswa Siswi Sekolah Dasar (Studi Kasus : SD Sariputra Jambi). Jurnal STIKOM Dinamika Bangsa, 14(2), 141-152. http:// doi.org/10.33998/processor.2019.10.637

[5] Arianto, J. (2019). Penerapan Data Mining Untuk Mengelompokan Penduduk Kurang Mampu Desa Sambirejo Timur Dengan Algoritma K-Medoids (Studi Kasus Kantor Kepala Desa Sambirejo Timur). Konferensi Nasional Teknologi
Informasi dan Komputer (KOMIK), 3(1), 569-573. http:// doi.org/10.30865/komik.v3i1.1660

[6] Wahyuni, S. (2018).Implementation of Data Mining to Analyze Drug Cases Using C4.5 Decision Tree. Journal of Physics : Conference Series, Electrical Engineering, Computer Science and Informatics (EECSI),1-6. http://doi.org/10.1088/17426596/970/1/012030

[7] Anggraini, S., Defit, S., Nurcahyo, G. N. (2018). Analisis Data Mining Penjualan Ban Menggunakan Algoritma C4.5. Jurnal Ilmu Teknik Elektro Komputer dan Informatika (JITEKI), 4(2), 136-143. http:// dex.doi.org/10.26555/jiteki.v4i2.11267

[8] Mellisa, I. ((2019). Building Data Mining Decision Tree Model for Predicting Employee Performance. Journal of Applied Information, Communication and Technology (JAICT). 6(2), 7586. http://doi.org/10.33555/ejaict.v6i2.79

[9] Supangat., Amna, A.R., Titasari, R. (2018). Implementasi Decision Tree C4.5 Untuk Menentukan Status Berat Badan dan Kebutuhan Energi Anak Usia 7-12 Tahun.TEKNIKA, 7(2), eISSN 2549-8045, ISSN 2549-8037,73-78. http:/l doi.org/10.34148/ teknika.v7i2.90

[10] Irawan, Y. (2021). Penerapan Algoritma Decision Tree C4.5 Untuk Prediksi Kelayakan Calon Pendonor Darah Dengan Klasifikasi Data Mining. Jurnal Teknologi Informasi dan $\begin{array}{llll}\text { Multimedia } & \text { (JTIM), 2(4), } & \text { 181-189. http:// }\end{array}$ doi.org/10.35746/jtim.v2i4.75

[11]Elfaladonna, F., \& Rahmadani, A. (2019). Analisa Metode Classification-Decision Tree dan Algoritma C4.5 Untuk Memprediksi Penyakit Diabetes Dengan Menggunakan Aplikasi Rapid Miner. Science and Information Technologi (SINTECH) $\begin{array}{llll}\text { Journal, } & 2(1), & \text { 73-78. }\end{array}$ doi.org/10.31598/sintechjournal.v2i1.293

[12] Asroni., Respati, B. M., Riyadi, S. (2018). Penerapan Algoritma C4.5 untuk Klasifikasi Jenis Pekerjaan Alumni di Universitas Muhammadiyah Yogyakarta. Jurnal Semesta Teknika, 21(2), 158-165. http://dx.doi.org/10.18196/st.212222

[13] Ginting, V. S., Kusrini., Taufiq. E. (2020). Implementasi Algoritma C4.5 Untuk Memprediksi Keterlambatan Pembayaran Sumbangan Pembangunan Pendidikan Sekolah Menggunakan Python. Jurnal Teknologi Informasi dan Komunikasi, 10(1), 3644. http:// doi.org/10.35585/inspir.v10i1.2535

[14]Handrianto, Y., \& Farhan, M. (2019). C.45 Algorithm for Classification of Causes of Landslides. Journal Publications \& Informatics Engineering Reaseach, 4(1), 120-127. http:// doi.org/10.33395/sinkron.v4i1.10154

[15]Limantara, C., \& Nababan, D. (2019). Klasifikasi Kepribadian Menggunakan Algoritma Decision Tree Berdasarkan Ten Item Personality Inventory. Jurnal CoreIT, 5(1), 8-12. http://dx.doi.org/10.18196/st.212222

[16]Rismayanti., Damayanti, F., Khairunnisa. (2018). Penerapan Data Mining Algoritma C4.5 dalam Menentukan Rekam Jejak Kinerja Dosen STT Harapan Medan. Jurnal \& Penelitian Teknik $\begin{array}{llll}\text { Informatika, } & 3(1), & 99-104 . & \mathrm{http}: / /\end{array}$ doi.org/10.33395/sinkron.v3i1.173

[17]Fitriani, Y., Defit, S., Nurcahyo, G. W. (2021). Prediksi Hasil Belajar Siswa Secara Daring pada Masa Pandemi COVID-19 Menggunakan Metode C4.5. Jurnal Sistem Informasi dan Teknologi, 3(3), 118-125. http:// doi.org/ 10.37034/jsisfotek.v3i3.149

[18]Febriyanto, D. B., Handoko, L., Wahyuli., Aisyah, H., Rumini. (2018). Implementasi Algoritma C4.5 Untuk Klasifikasi Tingkat Kepuasan Pembeli Online Shop. Jurnal Riset Komputer (JURIKOM). 5(6), 569-575. http:// doi.org/ 10.30865/jurikom.v5i6.1000 